\title{
Ventriculoperitoneal (VP) Shunt Survival in Patients Developing Hydrocephalus After Cranial Surgery
}

\author{
Farid KHAN ${ }^{1}$, Abdul REHMAN ${ }^{2}$, Muhammad Shahzad SHAMIM${ }^{1}$, Muhammad Ehsan BARI ${ }^{1}$ \\ ${ }^{1}$ The Aga Khan University Hospital, Department of Surgery, Section of Neurosurgery, Karachi, Sindh, Pakistan \\ ${ }^{2}$ The Aga Khan University, Department of Biological \& Biomedical Sciences, Karachi, Sindh, Pakistan
}

\section{ABSTRACT}

AIM: Ventriculoperitoneal (VP) shunt insertion remains the most popular method for the treatment of hydrocephalus despite its associated complications. We assessed VP shunt survival in a group of patients who had developed hydrocephalus following cranial surgery.

MATERIAL and METHODS: A retrospective charts review was done over a 10-year period at our institution. Kaplan-Meier survival curves and Log-Rank (Cox-Mantel) test were used to analyze various factors affecting VP shunt survival.

RESULTS: Among the 67 cases included, a total of 28 (46.3\%) patients had undergone cranial surgery for brain tumors. The overall rate of shunt failure was $14.9 \%$ at a mean follow-up of 16 months. Shunt failure in pediatric patients (20\%) was slightly higher than that in adult patients (13.5\%). The median time to first shunt failure was adversely influenced by a history of brain tumor $(p=0.019)$, prolonged antibiotic therapy $(p=0.018)$ and administration of steroids $(p=0.004)$.

CONCLUSION: Shunt survival was worse in patients who developed hydrocephalus following cranial surgery performed for brain tumors and those who received either steroids or prolonged antibiotic therapy. Thus post-cranial surgery hydrocephalus represents a unique subset of hydrocephalus.

KEYWORDS: Ventriculoperitoneal shunt, Hydrocephalus, Post-cranial surgery hydrocephalus, Shunt survival, Shunt complication, Shunt failure

\section{INTRODUCTION}

Hydrocephalus results from abnormal production, flow or absorption of cerebrospinal fluid (CSF) causing an "active distension" of ventricles of the brain (40). Left untreated, this condition can lead to rapid deterioration and adverse long-term outcomes, both in pediatric (45) and adult (28) patients. Prompt CSF diversion with ventriculoperitoneal (VP) shunt insertion remains the most popular treatment for hydrocephalus (17).

A number of classification schemes have been proposed to categorize hydrocephalus $(3,22,32,33,37)$. However, no single scheme is comprehensive enough to encompass all aspects of this diverse entity (40). The development of hydrocephalus following cranial surgery is a well-recognized phenomenon (29) and results from a combination of collateral damage incurred during the surgical procedure (19) and the alterations occurring later in the CSF circulation, cerebral blood flow (CBF) auto-regulation and cerebral compliance (47).

Complications resulting from VP shunts are notoriously common $(7,9,13,24)$ and have been a subject of extensive research. $(26,27,51)$ However, only a few studies have focused on VP shunt survival in patients who develop hydrocephalus as a consequence of cranial surgery itself. In this study, we report our experience of managing post-cranial surgery hydrocephalus in both pediatric and adult patients with particular emphasis on shunt complications and factors influencing shunt survival. 


\section{MATERIAL and METHODS}

A retrospective charts review was performed using the in-patient database at our institution. Confidentiality of patients' records was maintained and access to file records was strictly restricted to only concerned personnel. The study was exempted from formal ethical approval as per the institutional policy. Files were retrieved using ICD-9-CM (International Classification of Diseases, $9^{\text {th }}$ Revision-Clinical Modification) codes for "hydrocephalus" as the discharge diagnosis, and "ventriculoperitoneal shunt" as part of the procedure performed, so as to include all insertions and revisions. For the purpose of analysis, adult patients were defined as those who were 18 years of age or older. Each file was individually reviewed for patient demographics, clinical features, laboratory and radiological work-up, medical and surgical management, hospital stay and subsequent course. Clinical notes from consultations in neurosurgery clinics were specifically reviewed for the development of new complaints, any persistent symptoms and neurological deficits in terms of vision, cognition or motor function. Findings from shunt assessment were also recorded and, in cases of shunt malfunction, the cause and delay from first insertion to shunt revision was noted. Furthermore, for pediatric patients, data regarding antenatal ultrasound reports, mode of delivery and gestational age at birth were also collected.

All patients who developed hydrocephalus after cranial surgery (which was not noted on pre-operative scans) were included in the study. The primary outcome of interest was shunt failure and revision rate. For the purpose of this study, the definition of shunt failure proposed by Reddy et al (39) was used. Furthermore, shunt failure was categorized as: shunt infection, blockade and migration, cerebrospinal fluid ascites, or failure caused by an unknown factor.

Data was recorded using a structured, pre-tested questionnaire. For descriptive data, frequency, mean and standard deviation were calculated. Pearson's chi-square test, Student's t-test and Mann-Whitney $U$ test were used for comparison of proportions, means and medians respectively. A p-value of $<0.05$ was considered statistically significant in all cases. Kaplan-Meier curves were used to determine the duration from shunt placement to first malfunction. The Log Rank (MantelCox) test was used to determine factors affecting shunt survival. Statistical Package for Social Sciences (SPSS) version 20 (IBM SPSS Statistics 20) was used for both data entry and analysis.

\section{RESULTS}

A total of 439 patients had undergone VP shunt placement at our hospital during the period of this study. These consisted of 319 adult and 120 pediatric cases respectively. Amongst these patients, 67 (52 adult and 15 pediatric cases) had postcranial surgery as the etiology of hydrocephalus and thus were included in the final analysis (Figure 1).

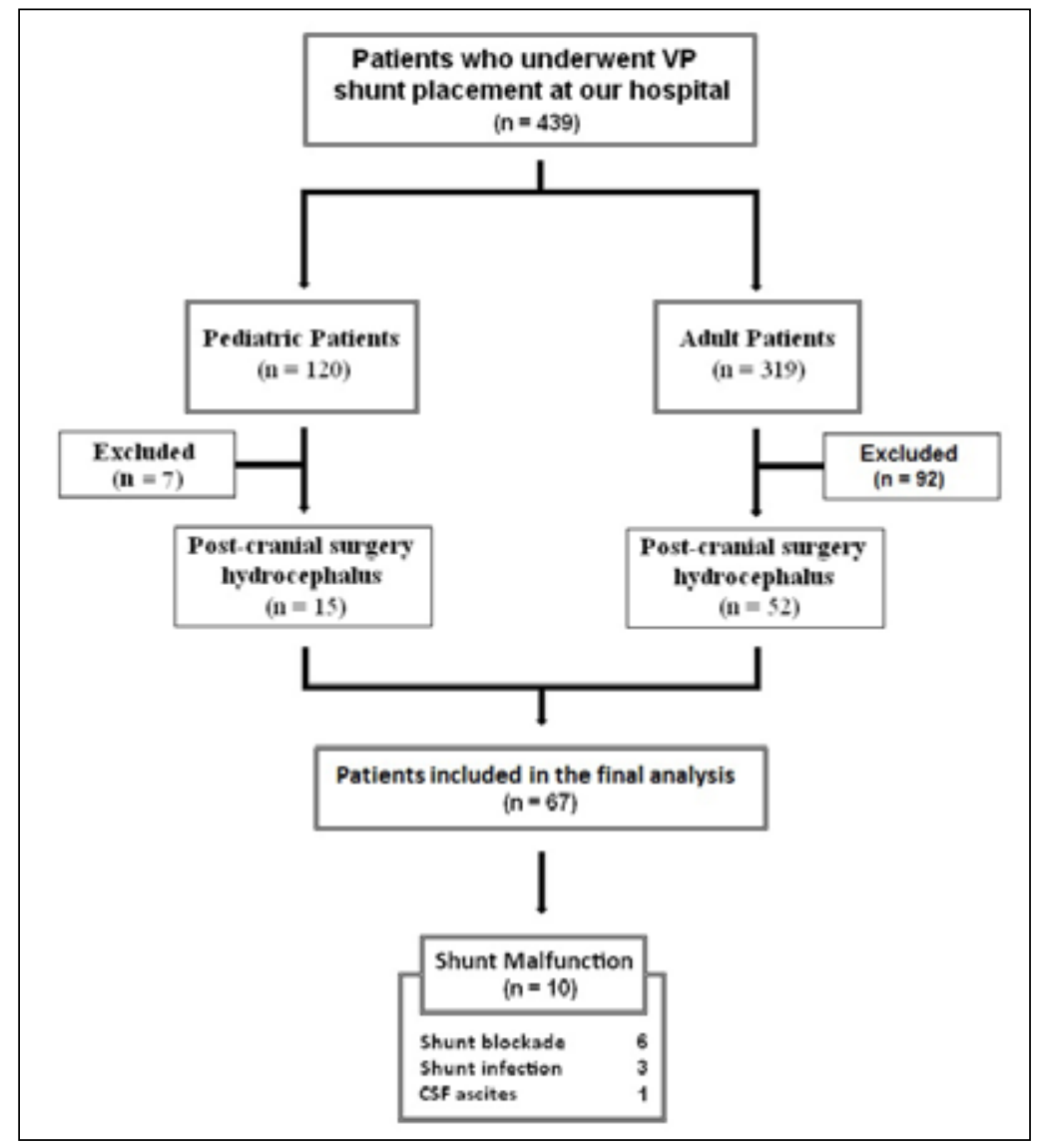

Figure 1: Flow diagram illustrating the inclusion and exclusion of both adult and pediatric patients for inclusion in the final analysis of this study. 


\section{Patient Demographics}

The mean age of all patients $(n=67)$ was 32.2 years. More specifically, the mean age for pediatric patients $(n=15)$ was 7.7 years ( 7 months to 15 years). For adult patients $(n=52)$, the mean age was 39.3 years (17 to 71 years). Almost twothird $(n=43,64.2 \%)$ of our patients were male.

Amongst the adult patients ( $n=52$ ), only five patients $(9.6 \%)$ had hypertension, while diabetes mellitus was noted in only one patient $(1.9 \%)$. Amongst the pediatric patients $(n=15)$, five patients $(33.3 \%)$ had spontaneous vaginal delivery, two (13.3\%) were born via Caesarean section and data was missing for the remaining patients $(n=8,53.3 \%)$. Six pediatric patients (40\%) were born full-term, while data was missing for the remaining 7 patients (60\%). This is summarized in Table I.

\section{Past History and Clinical Features}

A review of the past medical history of patients revealed that 28 patients $(46.3 \%)$ had a history of brain tumor resection. The

Table I: Demographics of Patients Included in Our Study $(n=67)$

\begin{tabular}{ll}
\hline Characteristics & N (\%) \\
\hline Sex & \\
\hline Male & $43(64.2 \%)$ \\
\hline Female & $24(35.8 \%)$ \\
\hline
\end{tabular}

Age

\begin{tabular}{lc} 
Mean age for all patients $(\mathrm{n}=67)$ & 32.2 years \\
\hline Mean age for pediatric patients $(\mathrm{n}=15)$ & 7.7 years \\
\hline Mean age for adult* patients $(\mathrm{n}=52)$ & 39.3 years \\
\hline Infants and young children $(<5$ years) & $6(8.9 \%)$ \\
\hline Older children (5-16 years) & $9(13.4 \%)$ \\
\hline Younger adults (16-40 years) & $29(43.3 \%)$ \\
\hline Middle-aged (40-65 years) & $16(23.9 \%)$ \\
\hline Elderly (>65 years) & $3(4.5 \%)$ \\
\hline
\end{tabular}

Mode of delivery for pediatric patients $(n=15)$

\begin{tabular}{ll}
\hline Vaginal delivery & $5(33.3 \%)$ \\
\hline Caesarean delivery & $2(13.3 \%)$ \\
\hline Missing data & $8(53.3 \%)$ \\
\hline Maturity at birth for pediatric patients $(\mathbf{n}=\mathbf{1 5})$ \\
\hline Full term & $6(40.0 \%)$ \\
\hline Missing data & $7(60.0 \%)$ \\
\hline Co-morbidities of adult patients $(\mathbf{n}=\mathbf{5 2})$ & \\
\hline Hypertension & $5(9.6 \%)$ \\
\hline Diabetes mellitus & $1(1.9 \%)$ \\
\hline
\end{tabular}

* In this study, all patients aged 16 years or more were considered as "adults." most common types of brain tumors included astrocytoma ( $\mathrm{n}=6,21.4 \%)$, medulloblastoma $(\mathrm{n}=4,14.3 \%)$ and meningioma ( $n=4,14.3 \%)$. The most common location for these brain tumors was the posterior fossa ( $n=10,35.7 \%$ ). Amongst the pediatric patients $(n=15)$, two patients $(13.3 \%)$ had a history of encephalocele repair. Other details regarding the past medical history of our study subjects is summarized in Table II.

The most common symptoms of patients included in our study were headache $(n=24,35.8 \%)$, altered consciousness or drowsiness ( $n=23,34.3 \%)$, gait disturbances $(n=19,28.4 \%)$, nausea or vomiting ( $n=16,23.9 \%)$, fever ( $n=10,14.9 \%)$, urinary or fecal incontinence $(n=10,14.9 \%)$ and weakness ( $n=10,14.9 \%)$. The initial physical examination performed

Table II: Past Medical and Surgical History of Patients ( $n=67)$

Past history N (\%)

Congenital abnormalities in pediatric patients $(n=15)$

\begin{tabular}{lc} 
Encephalocele & $2(13.3 \%)$ \\
\hline Arnold-Chiari malformation & $1(6.7 \%)$ \\
\hline Brain tumors & $28(46.3 \%)$ \\
\hline Traumatic brain injury & $8(11.9 \%)$
\end{tabular}

Types of brain tumors $(n=28)$

\begin{tabular}{|c|c|}
\hline Astrocytoma & $6(21.4 \%)$ \\
\hline Medulloblastoma & $4(14.3 \%)$ \\
\hline Meningioma & $4(14.3 \%)$ \\
\hline Oligodendroglioma & $2(7.1 \%)$ \\
\hline Craniopharyngioma & $2(7.1 \%)$ \\
\hline Hemangioblastoma & $2(7.1 \%)$ \\
\hline Ependymoma & $2(7.1 \%)$ \\
\hline Dermoid tumors & $2(7.1 \%)$ \\
\hline Glioblastoma multiforme & $1(3.6 \%)$ \\
\hline Pinealoblastoma & $1(3.6 \%)$ \\
\hline Central neurocytoma & $1(3.6 \%)$ \\
\hline Schwannoma & $1(3.6 \%)$ \\
\hline \multicolumn{2}{|c|}{ ocations of brain tumors $(n=28)$} \\
\hline Posterior fossa & $11(39.3 \%)$ \\
\hline Cerebellopontine angle & $4(14.3 \%)$ \\
\hline Lateral ventricle & $4(14.3 \%)$ \\
\hline Frontal lobe & $4(14.3 \%)$ \\
\hline Middle fossa & $3(10.7 \%)$ \\
\hline Para- or suprasellar & $1(3.6 \%)$ \\
\hline Fourth ventricle & $1(3.6 \%)$ \\
\hline
\end{tabular}


on these patients revealed that the mean and median GCS at presentation was 13 and 14 respectively. Three (4.5\%) patients were comatose $(\mathrm{GCS} \leq 8)$ on presentation, while another 23 patients $(34.3 \%)$ had motor deficits (Table III).

Laboratory work-up of our patients included serum chemistry, blood counts, blood culture and radiologic investigations. Lumbar puncture was performed in 40 patients (59.7\%) and further details are provided in Table III.

\section{Management}

The mean and median duration of hospital stay for our patients was 11.7 days and five days respectively. Antibiotics were administered to 61 (91.0\%) patients and most of these patients $(n=52,85.2 \%)$ received antibiotics for a period of one week or less. Mannitol was administered to six patients (8.9\%), steroids and anti-convulsants were required in $12(17.9 \%)$ and $20(29.9 \%)$ patients respectively. All patients included in the study underwent VP shunt placement. A right-sided VP shunt was inserted in $45(67.2 \%)$ patients, while external ventricular drains were placed in 49 (73.1\%) patients, prior to placement of VP shunt. These results are summarized in Table IV.

\section{Clinical Follow-Up}

Regular outpatient follow up was noted in 55 (82.1\%) patients for a mean duration of 485.4 days. The remaining patients $(n=$ $12,17.9 \%$ ) followed up for only one or two clinic visits following VP shunt placement. Amongst the patients who followed up regularly $(n=55)$, the most common complaints reported by the patients were headache $(n=6,10.9 \%)$, drowsiness or alteration in consciousness $(n=2,3.6 \%)$ and seizures $(n=2$, $3.6 \%)$. New-onset cognitive and visual deficits were noted in two (3.6\%) and four (7.2\%) patients respectively. The median Karnofsky Performance Status (KPS) score of patients who followed up regularly $(n=55)$ was 70 (Table IV). Among the study subjects included in this study, only one (1.5\%) pediatric patient (aged 4 years) died in the immediate post-operative period.

\section{Shunt Complications}

The overall rate of shunt failure noted in our study was $14.9 \%$ $(n=10)$. Shunt revision was performed in all of these cases. Blockade was the most common cause of shunt failure $(n=$ $6,60 \%)$ followed by infection $(n=3,30 \%)$ and CSF ascites $(n=1,10 \%)$. The characteristics of patients who suffered shunt failure in our study are given in Table V. Using KaplanMeier survival analysis, the shunt failure rate at one month and six months was calculated to be $8.9 \%$ and $13.4 \%$ respectively. The shunt failure rate among adult $(n=52)$ and pediatric patients $(n=15)$ was $13.5 \%$ and $20 \%$ respectively. However, the difference was not statistically significant $(p=0.531)$. No statistically significant difference was noted in the shunt failure rate between male and female patients $(p=0.677)$, those with a history of brain tumor $(p=0.412)$ or those with a history of traumatic brain injury $(p=0.837)$.

\section{Factor Affecting Time to First Shunt Failure (VP Shunt Survival)}

The median time from shunt placement to shunt failure was
22.5 days ranging from one to 243 days (Figure 2). As given in Figure 3, Kaplan-Meier plot showed that the median time to first shunt failure was significantly less for patients who developed hydrocephalus following cranial surgery for brain

Table III: Clinical Features of Study Subjects $(n=67)$

\begin{tabular}{|c|c|}
\hline Subjective symptoms & N (\%) \\
\hline Headache & $24(35.8 \%)$ \\
\hline Drowsiness or altered consciousness & $23(34.3 \%)$ \\
\hline Gait disturbances & $19(28.4 \%)$ \\
\hline Nausea and vomiting & $16(23.9 \%)$ \\
\hline Urinary or fecal incontinence & $10(14.9 \%)$ \\
\hline Weakness & $10(14.9 \%)$ \\
\hline Fever & $10(14.9 \%)$ \\
\hline Vision disturbances & $4(6.0 \%)$ \\
\hline Unusual increase in head size & $4(6.0 \%)$ \\
\hline Seizures & $4(6.0 \%)$ \\
\hline Confusion & $3(4.5 \%)$ \\
\hline Findings on physical examination & $\mathbf{N}(\%)$ \\
\hline Tachycardia (on presentation) & $5(7.5 \%)$ \\
\hline \multicolumn{2}{|l|}{ Glasgow coma scale (on presentation) } \\
\hline Mean GCS & 13 \\
\hline Median GCS & 14 \\
\hline Comatose patients (GCS $\leq 8$ ) & $3(4.5 \%)$ \\
\hline Motor deficits on presentation & $23(34.3 \%)$ \\
\hline Laboratory and radiologic data & $\mathbf{N}(\%)$ \\
\hline Lumbar puncture & 40 (59.7\%) \\
\hline
\end{tabular}

Findings on CSF examination $(n=40)$

\begin{tabular}{lc}
\hline Normal findings & $23(57.5 \%)$ \\
\hline CSF pleocytosis or hypoglycorrhachia & $10(25.0 \%)$ \\
\hline Other abnormalities & $3(7.5 \%)$ \\
\hline Missing data & $4(10.0 \%)$ \\
\hline Findings of CSF culture $(\mathrm{n}=40)$ & $29(80.6 \%)$ \\
\hline No growth & $3(7.5 \%)$ \\
\hline Missing data & $7(19.4 \%)$ \\
\hline Positive culture & \\
\hline Type of pathogen $(\mathrm{n}=7)$ & $5(71.4 \%)$ \\
\hline Gram negative rods & $2(28.6 \%)$ \\
\hline Gram positive cocci
\end{tabular}

CSF: Cerebrospinal fluid, GCS: Glasgow Coma Scale. 
tumors as compared to others ( $p=0.019$, Log Rank). The type $(p=0.317$, Log Rank) or location ( $p=0.273$, Log Rank) of brain tumor did not have a significant impact on the median time to first shunt failure. Moreover, there was no statistically significant difference in the median time to first shunt failure between pediatric and adult patients ( $p=0.365$, Log Rank), or between male and female patients ( $p=0.868$, Log Rank). Time to first shunt failure was also not significantly different among patients of different age groups ( $p=0.620$, Log Rank).
In our study, median shunt survival time was found to be significantly different between patients who had received antibiotics for a duration of one week or less and those who had received antibiotics for longer periods ( $p=0.018$, Log Rank) (Figure 4). Furthermore, as given in Figure 5 , shunt survival was particularly worse in patients who were administered steroids as part of their in-hospital management compared to those who were not administered steroids ( $p=0.004$, Log Rank). The difference in the median time to first shunt failure among

Table IV: Medical and Surgical Aspects of Management and Findings on Follow-up $(n=67)$

\begin{tabular}{|c|c|c|c|}
\hline Medical management & $\mathbf{N}(\%)$ & Surgical management & $\mathbf{N}(\%)$ \\
\hline Median duration of stay & 5 days & Ventriculoperitoneal shunt & 67 (100\%) \\
\hline Antibiotics & $61(91.0 \%)$ & Side of shunt $(\mathrm{n}=67)$ & \\
\hline Mannitol & $6(8.9 \%)$ & Right-sided VP shunt & $45(67.2 \%)$ \\
\hline Acetazolamide & $2(3.0 \%)$ & Left-sided VP shunt & $22(32.8 \%)$ \\
\hline Anticonvulsants & $20(29.9 \%)$ & Extra-ventricular drains & $49(73.1 \%)$ \\
\hline Steroids & $12(17.9 \%)$ & Post-operative physiotherapy & $27(23.9 \%)$ \\
\hline \multicolumn{4}{|l|}{ Duration of antibiotic therapy $(\mathrm{n}=61)$} \\
\hline Up to one week & $52(85.2 \%)$ & & \\
\hline More than one week & $9(14.8 \%)$ & & \\
\hline Clinical follow-up & & $\mathbf{N}(\%)$ & \\
\hline Patients who followed up regularly & & $55(82.1 \%)$ & \\
\hline Patients lost to follow up & & $12(17.9 \%)$ & \\
\hline Mean duration of follow up & & 485.4 days & \\
\hline \multicolumn{4}{|l|}{ Subjective complaints $(\mathrm{n}=55)$} \\
\hline Headache & & $6(10.9 \%)$ & \\
\hline Drowsiness or altered consciousness & & $2(3.6 \%)$ & \\
\hline Seizures & & $2(3.6 \%)$ & \\
\hline Nausea or vomiting & & $2(3.6 \%)$ & \\
\hline Vision disturbances & & $1(1.8 \%)$ & \\
\hline Urinary or fecal incontinence & & $1(1.8 \%)$ & \\
\hline \multicolumn{4}{|l|}{ Neurologic examination findings $(\mathrm{n}=55)$} \\
\hline New-onset visual deficits & & $2(3.6 \%)$ & \\
\hline New-onset cognitive deficits & & $4(7.2 \%)$ & \\
\hline \multicolumn{4}{|l|}{ Wound examination $(\mathrm{n}=55)$} \\
\hline Healthy wounds & & $49(89.1 \%)$ & \\
\hline Missing data & & $6(10.9 \%)$ & \\
\hline \multicolumn{4}{|l|}{ Karnofsky Performance Status $(\mathrm{n}=55)$} \\
\hline Median score & & 70 & \\
\hline
\end{tabular}

VP shunt: Ventriculoperitoneal shunt. 
patients who had received anti-convulsants $(p=0.121)$ or mannitol ( $p=0.267$ ) failed to reach statistical significance. The placement of external-ventricular drains was also not noted to have any statistically significant influence on VP shunt survival ( $p=0.237$, Log Rank).

\section{DISCUSSION}

VP shunt insertion has remained the most popular method for treatment of hydrocephalus in adults (17). A few additions have also been made to the list of available treatment options with the most noteworthy being endoscopic third ventriculostomy

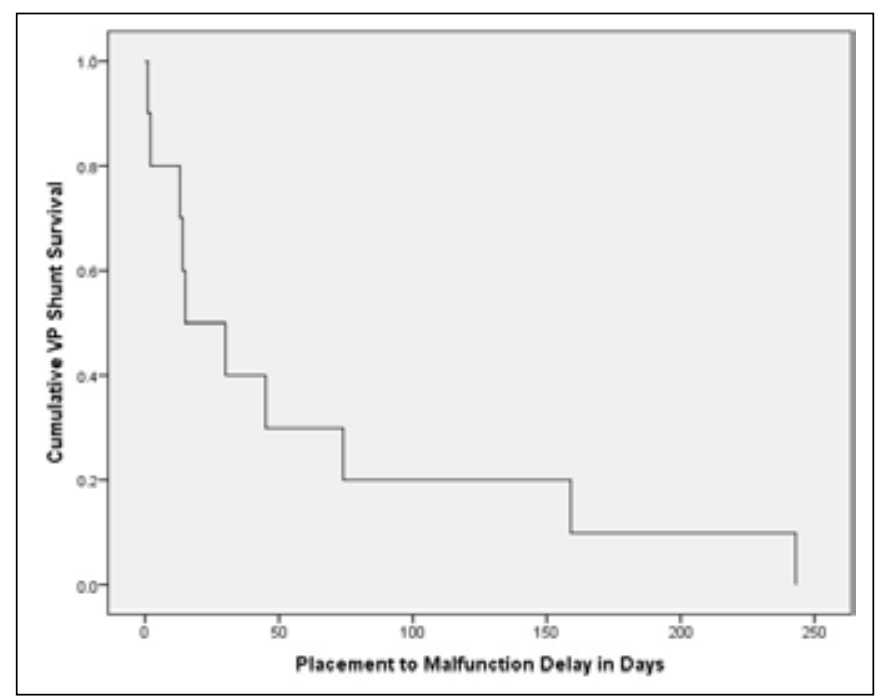

Figure 2: Kaplan-Meier shunt survival analysis for post-cranial surgery hydrocephalus shows overall median time to first shunt failure was 22.5 days with shunt survival time ranging from a minimum of one day to a maximum of 243 days.

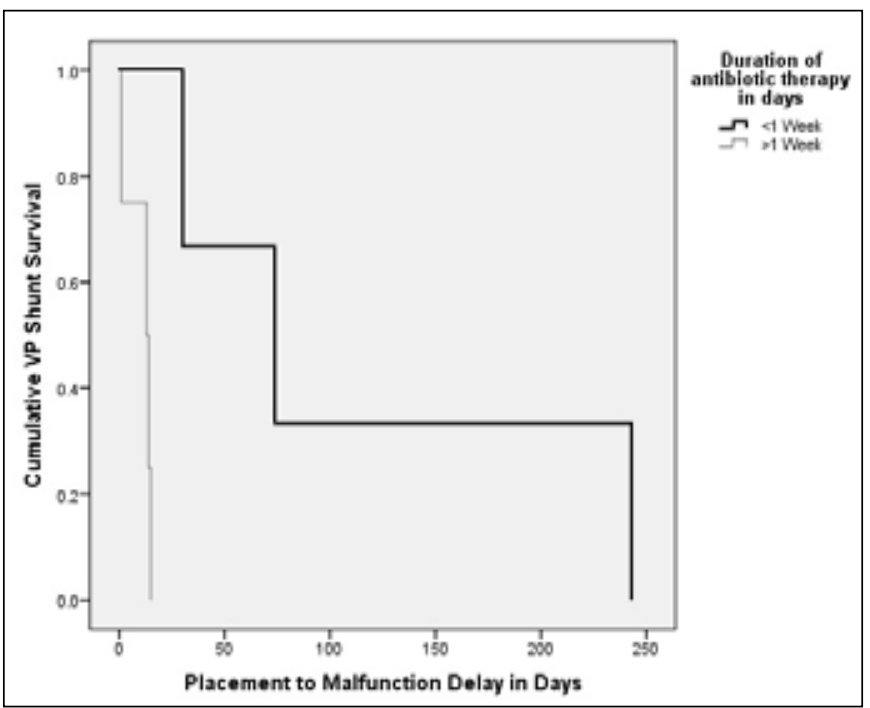

Figure 4: Kaplan-Meier shunt survival analysis for post-cranial surgery hydrocephalus shows that patients who had received antibiotics for a duration of greater than one week had significantly reduced shunt survival ( $p=0.018$, Log Rank).
(ETV) (20). However, this method is preferred mainly in noncommunicating hydrocephalus $(15,18,23)$. In patients with hydrocephalus secondary to infective etiologies $(4,6,21,31)$ or meningomyelocele $(4,11,48)$ as well as in neonates and infants $(4,15,18,48,50)$, the effectiveness of ETV remains questionable. Thus VP shunt placement continues to be an important corner-stone in the management of hydrocephalus in both adult and pediatric patients.

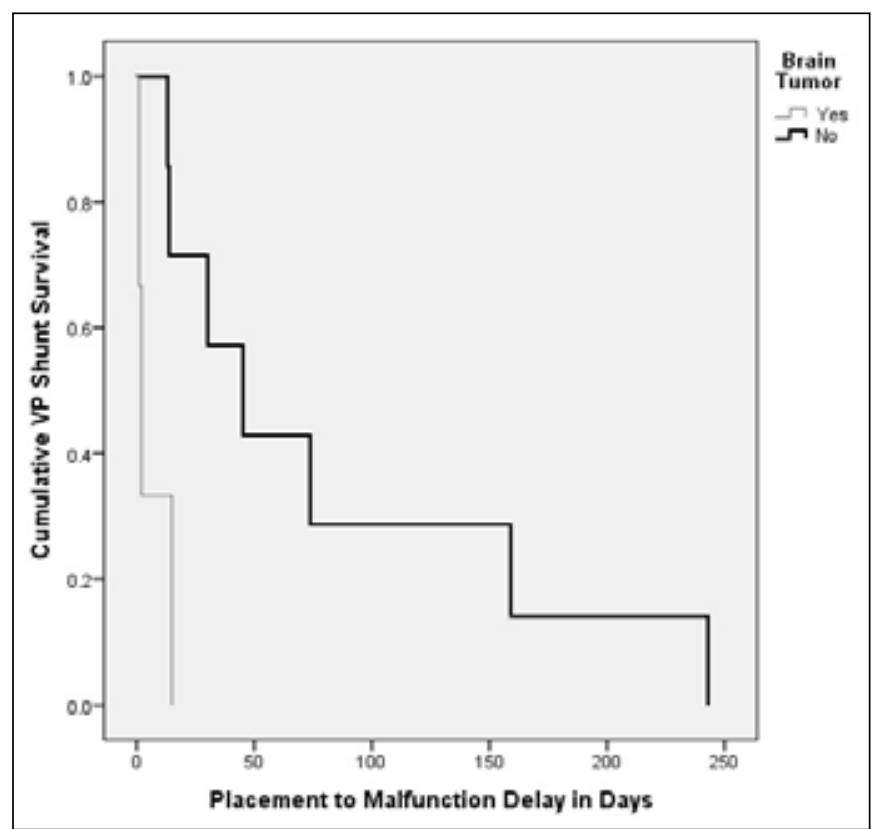

Figure 3: Kaplan-Meier shunt survival analysis shows worse shunt survival in patients developing hydrocephalus following cranial surgery performed for brain tumors ( $p=0.019$, Log Rank).

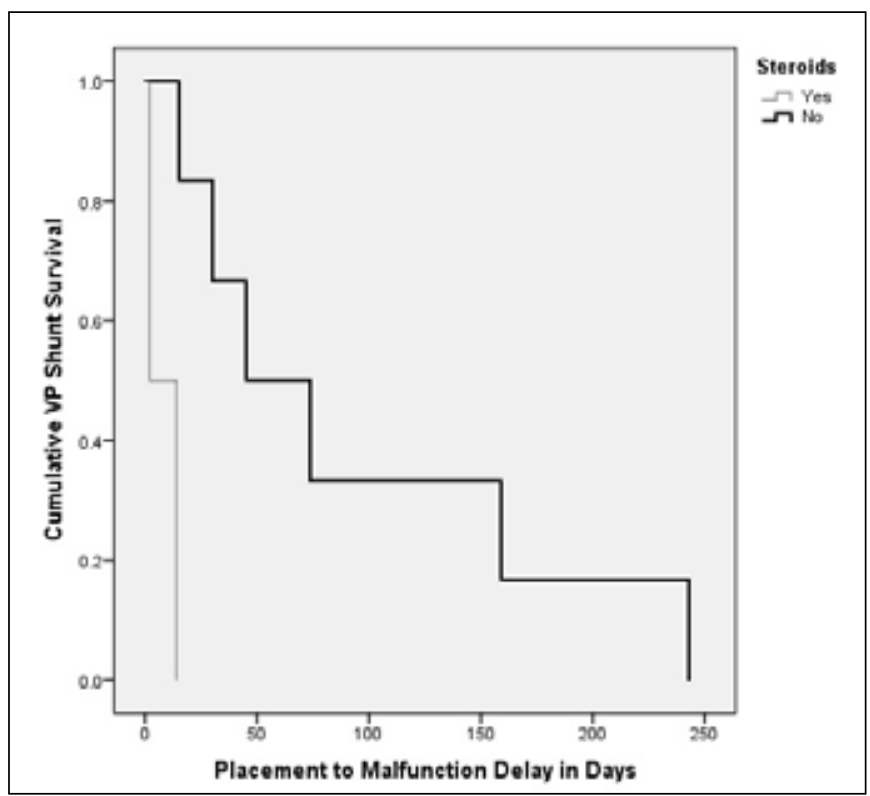

Figure 5: Kaplan-Meier shunt survival analysis for post-cranial surgery hydrocephalus showing the adverse impact of steroids on the median time to first shunt failure ( $p=0.004$, Log Rank). 
Table V: Details of Patients Who Experienced Shunt Failure in Our Study $(n=10)$

\begin{tabular}{|c|c|c|c|c|c|}
\hline No & $\begin{array}{l}\text { Type of shunt } \\
\text { malfunction }\end{array}$ & $\begin{array}{l}\text { Placement to shunt } \\
\text { failure time (days) }\end{array}$ & History of brain tumor & Antibiotic therapy & $\begin{array}{c}\text { Steroids } \\
\text { administered }\end{array}$ \\
\hline 1. & Shunt blockade & 1 & Schwannoma at left CP angle & More than one week & No \\
\hline 2. & Shunt blockade & 2 & Ependymoma of lateral ventricle & -- & Yes \\
\hline 3. & Shunt blockade & 13 & -- & More than one week & No \\
\hline 4. & Shunt infection & 14 & -- & More than one week & Yes \\
\hline 5. & Shunt blockade & 15 & Suprasellar craniopharyngioma & More than one week & No \\
\hline 6. & Shunt infection & 30 & -- & Less than one week & No \\
\hline 7. & CSF ascites & 45 & -- & -- & No \\
\hline 8. & Shunt blockade & 74 & -- & Less than one week & No \\
\hline 9. & Shunt infection & 159 & -- & -- & No \\
\hline 10. & Shunt blockade & 243 & -- & Less than one week & No \\
\hline
\end{tabular}

CP angle: Cerebellopontine angle.

Multiple studies have reported the impact of etiology of hydrocephalus on VP shunt survival in both adult and pediatric patients $(26,27,44,49,51)$. In the present retrospective file review, we specifically studied patients who had developed hydrocephalus following cranial surgery and subsequently underwent VP shunt insertion. The impact of various factors like patient demographics, past medical history and inpatient management on shunt survival was analyzed. Followup of patients in neurosurgery clinics were also reviewed to determine performance status and the development of any new complaints.

The VP shunt failure rate observed in our study for post-cranial surgery hydrocephalus was $14.9 \%$. This is considerably lower than the overall VP shunt failure rate (inclusive of all etiologies) reported by previous studies from other parts of the world (25, $30,34,35,49,51)$. However, the shunt failure rate observed in our study is in line with more recent reports published in the literature, even from the developing world $(12,14)$.

The shunt failure rate for pediatric patients $(20 \%)$ included in our study was slightly higher than that for adult patients (13.5\%), although the difference failed to reach statistical significance. This may be explained by the technical difficulties encountered in both the surgical and medical management of such patients $(27,44,49)$. Other demographic factors like sex, age and co-morbid conditions did not influence the frequency of shunt failure in this study. A predominance of male patients (64.2\%) was noted in our study and is in accordance with a previous report from our own hospital (38). This trend has also been noted in other studies from the developing world $(12,24)$. Gender as an independent risk factor for shunt failure remains unsettled $(12,49,51)$. Moreover, previous studies failed to show a significant impact of patient's age on VP shunt failure (51). However, neonates and infants were noted to have a higher rate of shunt failure in the report by Di Rocco et al (7).
The median time from shunt placement to first shunt failure noted in our study was 22.5 days, which is comparable to that reported by other studies $(12,14)$. As mentioned previously, the development of hydrocephalus following cranial surgery (29) may be attributed to the direct collateral damage incurred during the surgical procedure (19). Theoretically, therefore, the indication for which cranial surgery was performed, the expertise of the operating surgeon, the surgical techniques employed as well as other patient factors may influence the survival of VP shunts placed in such patients. In our study, patients who developed hydrocephalus following cranial surgery performed for brain tumors had a significantly decreased median time to first shunt failure. This may be explained by the extensive manipulation and injury to tissues incurred during resection of neoplastic disease as well as the alterations in cerebral blood flow and auto-regulation that develops after the procedure $(19,29,46,47)$.

An interesting finding noted in our study was that patients who had received steroids as part of their in-patient management had worse shunt survival. Corticosteroids are often employed in the initial management of patients with brain tumors (1, 42), tuberculous meningitis (43) and other infections like neurocysticercosis (41). In our study, corticosteroids were employed in the management of 12 patients, out of which two patients developed shunt failure. However, the placement to malfunction time in both these patients (two days and 14 days) was much shorter than that of other patients with shunt failure, who were not on steroids (median of 59.5 days). The benefit of long-term steroid therapy in hydrocephalus secondary to infectious etiologies has been reported in a few studies (41). However, Foley et al. (10) reported the worsening of hydrocephalus after treatment with corticosteroids in a patient with neurosarcoidosis. Steroids may possibly worsen shunt survival by down-regulating the process of protein expression within fibroblasts leading to inhibition of anabolic processes. $(2,14)$ This can hinder the process of healing and granulation 
tissue formation, with subsequent risk of dehiscence of skin, subcutaneous tissue and meningeal layers. $(2,14)$ The impact of steroids on the shunt survival time in patients developing hydrocephalus following cranial surgery requires further evaluation through larger prospective studies.

Another intriguing finding noted in our study was that patients who received prolonged antibiotic therapy were more likely to experience early shunt failure. While the role of short-term prophylactic antibiotics in neurosurgery is well-established (9), many studies have also shown that prolonged use of antibiotics can promote anti-microbial resistance and serve as a means of "natural selection" for more virulent pathogens (8). Infection with such organisms can prove to be detrimental for shunt survival $(5,16,36)$. Additionally, some evidence also suggests that prolonged use of antibiotics can impair the natural process of suppurative inflammation and result in the formation of conglomerate micro-abscesses (25). These can impede CSF flow through the shunt system, ultimately culminating in VP shunt failure.

Our study was subject to a number of limitations, which must be kept in mind before reaching a conclusion. As mentioned before, hydrocephalus developing after cranial surgery is intimately related to the surgical procedure itself. At our hospital, surgical procedures were performed by seven different neurosurgeons. However, in the present study, we did not compare the shunt failure rate among different neurosurgeons. Moreover, shunt devices and preference of surgical methods were not analyzed separately. Only a single type of shunt was placed in all patients included in our study and therefore, the influence of the type of shunt on subsequent shunt survival could not be assessed. Among the patients included in the study, a small proportion of patients did not follow-up regularly after the surgical procedure, which may have led to under-detection of delayed shunt complications. Lastly, a substantial number of patients who had undergone VP shunt placement at our hospital were excluded from the analysis due to unavailability of medical records and missing data. This may have resulted in possible selection bias.

Despite the limitations of this being a retrospective study, it bears significant value as it is one of the few studies to assess shunt failure in patients with post-cranial surgery hydrocephalus. Hydrocephalus developing after cranial surgery represents a unique subset of patients with hydrocephalus and little is known about the determinants of shunt failure in these patients. Our study sheds some light on VP shunt survival in such patients and may provide a direction for future research. The association of steroid therapy with worsened shunt survival observed in our study needs to be explored further through larger prospective studies.

\section{- CONCLUSION}

Post-cranial surgery hydrocephalus represents a unique subset of hydrocephalus. Patients who developed hydrocephalus following cranial surgery performed for brain tumors had worse shunt survival. Moreover, patients who had received antibiotics for more than one week and those who had been administered steroids were also at high risk of early shunt failure. Further studies are needed to accurately characterize and elucidate the mechanism of this deleterious impact of steroids on shunt survival in this particular group of patients.

\section{REFERENCES}

1. Albright $\mathrm{L}$, Reigel $\mathrm{DH}$ : Management of hydrocephalus secondary to posterior fossa tumors. J Neurosurg 46:52-55, 1977

2. Bebawy JF: Perioperative steroids for peritumoral intracranial edema: A review of mechanisms, efficacy and side effects. J Neurosurg Anesthesiol 24:173-177, 2012

3. Beni-Adani L, Biani N, Ben-Sirah L, Constantini S: The occurrence of obstructive vs absorptive hydrocephalus in newborns and infants: Relevance to treatment choices. Childs Nerv Syst 22:1543-1563, 2006

4. Buxton N, Macarthur D, Malluci C, Punt J, Vloeberghs M: Neuroendoscopic third ventriculostomy in patients less than 1 year old. Pediatr Neurosurg 29:73-76, 1998

5. Choksey MS, Malik IA: Zero tolerance to shunt infections: Can it be achieved? J Neurol Neurosurg Psychiatry 75:87-91, 2004

6. Cinalli G, Sainte-Rose C, Chumas P, Zerah M, Brunelle F, Lot G, Pierre-Kahn A, Renier D: Failure of third ventriculostomy in the treatment of aqueductal stenosis in children. J Neurosurg 90:448-454, 1999

7. Di Rocco C, Marchese E, Velardi F: A survey of the first complication of newly implanted CSF shunt devices for the treatment of nontumoral hydrocephalus. Cooperative survey of the 1991-1992 Education Committee of the ISPN. Childs Nerv Syst 10:321-327, 1994

8. Enger P, Svendsen F, Wester K: CSF shunt infections in children: Experiences from a population-based study. Acta Neurochir (Wien) 145:243-248, 2003

9. Fan-Harvard $P$, Nataha MC: Treatment and prevention of infections of cerebrospinal fluid shunts. Clin Pharm 6:866880,1987

10. Foley KT, Junck HL: Progression of hydrocephalus during corticosteroid therapy for neurosarcoidosis. Postgrad Med J 65:481-484, 1989

11. Fukuhara T, Vorster SJ, Luciano MG: Risk factors for failure of endoscopic third ventriculostomy for obstructive hydrocephalus. Neurosurgery 46:1100-1111, 2000

12. Gathura E, Poenaru D, Bransford R, Albright AL: Outcomes of ventriculoperitoneal shunt insertion in Sub-Saharan Africa. J Neurosurg Pediatr 6:329-335, 2010

13. Ghritlaharey RK, Budhwani KS, Shrivastava DK, Srivastava $\mathrm{J}$ : Ventriculoperitoneal shunt complications needing shunt revision in children: A review of 5 years of experience with 48 revisions. Afr J Pediatr Surg 9:32, 2012

14. Goldschmidt E, Hem S, Ajler P, lelpi M, Loresi M, Giunta D, Carrizo A, Yampolsky C, Argibay P: A new model for dura mater healing: Human dural fibroblast culture. Neurol Res 35: 300-307, 2013

15. Goumnerova LC, Frim DM: Treatment of hydrocephalus with third ventriculocisternostomy: Outcome and CSF flow patterns. Pediatr Neurosurg 27:149-152, 1997

16. Gutiérrez-González R, Boto GR, Pérez-Zamarrón Á: Cerebrospinal fluid diversion devices and infection. A comprehensive review. Eur J Clin Microbiol Infect Dis 31(6):889-897, 2012 
17. Hamilton MG: Treatment of hydrocephalus in adults. Semin Pediatr Neurol 16:34-41, 2009

18. Hopf NJ, Grunert P, Fries G, Resch KDM, Perneczky A: Endoscopic third ventriculostomy: Outcome analysis of 100 consecutive procedures. Neurosurgery 44: 795-806, 1999

19. Huang APH, Tu YK, Tsai YH, Chen YS, Hong WC, Yang CC, Kuo LT, Su IC, Huang SH, Huang SJ: Decompressive craniectomy as the primary surgical intervention for hemorrhagic contusion. J Neurotrauma 25: 1347-1354, 2008

20. Jallo GI, Kothbauer KF, Abbott IR: Endoscopic third ventriculostomy. Neurosurg Focus 19: E11, 2005

21. Javadpour M, Mallucci C, Brodbelt A, Golash A, May P: The impact of endoscopic third ventriculostomy on the management of newly diagnosed hydrocephalus in infants. Pediatr Neurosurg 35:131-135, 2001

22. Johnston I, Teo C: Disorders of CSF hydrodynamics. Child Nerv Syst 16: 776-799, 2000

23. Jones RFC, Stening WA, Brydon M: Endoscopic third ventriculostomy. Neurosurgery 26:82-92, 1990

24. Kinasha ADA, Kahamba JF, Semali IT: Complications of ventriculoperitoneal shunts in children in Dar es Salaam. East Cent Afr J Surg 10: 55-59, 2005

25. Korinek AM, Golmard JL, Elcheick A, Bismuth R, Van Effenterre $R$, Coriat P, Puybasset L: Risk factors for neurosurgical site infections after craniotomy: A critical reappraisal of antibiotic prophylaxis on 4578 patients. Br J Surg 19:155-162, 2005

26. Lazareff JA, Peacock W, Holly L, Halen JV, Wong A, Olmstead C: Multiple shunt failures: An analysis of relevant factors. Childs Nerv Syst 14:271-275, 1998

27. Liptak GS, McDonald JV: Ventriculoperitoneal shunts in children: Factors affecting shunt survival. Pediatr Neurosci 12: 289-293, 1985

28. Malm J, Kristensen B, Stegmayr B, Fagerlund M, Koskinen LO: Three-year survival and functional outcome of patients with idiopathic adult hydrocephalus syndrome. Neurology 55: 576-578, 2000

29. Margules A, Jallo J: Complications of decompressive craniectomy. JHN Journal 5: 9-12, 2010

30. McGirt MJ, Leveque JC, Wellons IJC, Villavicencio AT, Hopkins JS, Fuchs HE, George TM: Cerebrospinal fluid shunt survival and etiology of failures: A seven-year institutional experience. Pediatr Neurosurg 36: 248-255, 2002

31. Mohanty A, Vasudev MK, Sampath S, Radhesh S, Kolluri VRS: Failed endoscopic third ventriculostomy in children: Management options. Pediatr Neurosurg 37: 304-309, 2002

32. Mori K: Hydrocephalus-Revision of its definition and classification with special reference to "intractable infantile hydrocephalus". Childs Nerv Syst 6:198-204, 1990

33. Oi S, Di Rocco C: Proposal of "evolution theory in cerebrospinal fluid dynamics" and minor pathway hydrocephalus in developing immature brain. Childs Nerv Syst 22:662-669, 2006

34. Paulsen AH, Lundar T, Lindegaard KF: Twenty-year outcome in young adults with childhood hydrocephalus: Assessment of surgical outcome, work participation, and health-related quality of life. J Neurosurg Pediatr 6:527-535, 2010

35. Piatt JrJH, Garton HJL: Clinical diagnosis of ventriculoperitoneal shunt failure among children with hydrocephalus. Pediatr Emerg Care 24:201, 2008
36. Pirotte BJM, Lubansu A, Bruneau M, Loqa C, Van Cutsem $\mathrm{N}$, Brotchi J: Sterile surgical technique for shunt placement reduces the shunt infection rate in children: Preliminary analysis of a prospective protocol in 115 consecutive procedures. Child's Nerv Syst 23: 1251-1261, 2007

37. Raimondi AJ: A unifying theory for the definition and classification of hydrocephalus. Childs Nerv Syst 10:2-12, 1994

38. Rashid QTA, Salat MS, Enam K, Kazim SF, Godil SS, Enam SA, Iqbal SP, Azam SI: Time trends and age-related etiologies of pediatric hydrocephalus: Results of a groupwise analysis in a clinical cohort. Child's Nerv Syst 28(2):221-227, 2012

39. Reddy GK, Bollam P, Shi R, Guthikonda B, Nanda A: Management of adult hydrocephalus with ventriculoperitoneal shunts: Long-term single-institution experience. Neurosurgery 69: 774-781, 2011

40. Retake HL: The definition and classification of hydrocephalus: A personal recommendation to stimulate debate. Cerebrospinal Fluid Res 5:2, 2008

41. Roman RAS, Soto-Hernández JL, Sotelo J: Effects of prednisone on ventriculoperitoneal shunt function in hydrocephalus secondary to cysticercosis: A preliminary study. J Neurosurg 84:629-633, 1996

42. Schmid UD, Seller RW: Management of obstructive hydrocephalus secondary to posterior fossa tumors by steroids and subcutaneous ventricular catheter reservoir. J Neurosurg 65:649-653, 1986

43. Schoeman JF, Van Zyl LE, Laubscher JA, Donald PR: Effect of corticosteroids on intracranial pressure, computed tomographic findings, and clinical outcome in young children with tuberculous meningitis. Pediatrics 99: 226-231, 1997

44. Serlo W, Fernell E, Heikkinen E, Anderson H, Wendt L: Functions and complications of shunts in different etiologies of childhood hydrocephalus. Child's Nerv Syst 6:92-94, 1990

45. Sgouros S, Malluci C, Walsh AR, Hockley AD: Long-term complications of hydrocephalus. Pediatr Neurosurg 23:127132, 1995

46. Stein BM, Tenner MS, Fraser RAR: Hydrocephalus following removal of cerebellar astrocytomas in children. J Neurosurg 36:763-768, 1972

47. Stiver SI: Complications of decompressive craniectomy for traumatic brain injury. Neurosurg Focus 26:E7, 2009

48. Teo C, Jones R: Management of hydrocephalus by endoscopic third ventriculostomy in patients with myelomeningocele. Pediatr Neurosurg 25:57-63, 1996

49. Tuli S, Drake J, Lawless J, Wigg M, Lamberti-Pasculli M: Risk factors for repeated cerebrospinal shunt failures in pediatric patients with hydrocephalus. J Neurosurg 92:31-38, 2000

50. Warf BC, Tracy S, Mugamba J: Long-term outcome for endoscopic third ventriculostomy alone or in combination with choroid plexus cauterization for congenital aqueductal stenosis in African infants. J Neurosurg Pediatr 10:108-111, 2012

51. Wu Y, Green NL, Wrensch MR, Zhao S, Gupta N: Ventriculoperitoneal shunt complications in California: 1990 to 2000. Neurosurgery 61: 557-563, 2007 